- Revista de Iniciação à Docência, v. 2, n. 1, 2017 Publicação: dezembro, 2017 - ISSN 2525-4332

\title{
A APLICAÇÃO DE METODOLOGIAS ATIVAS NO ENSINO DE FÍSICA EM UMA TURMA DA EJA DO CENTRO NOTURNO DE EDUCAÇÃO DA BAHIA/CENEB/VCA-BAHIA
}

\author{
Carolina Brito Souza ${ }^{1}$ \\ Clenivaldo Ferreira Januário² \\ Ferdinand Martins da Silva ${ }^{3}$ \\ Gabriel Alves Santos 4 \\ Geovana Brito de Oliveira de Jesus 5 \\ Henrique Melo Ferraz ${ }^{6}$ \\ Jacqueline Teixeira Santos 7 \\ Luana Prates de Oliveira ${ }^{8}$ \\ Stela Almeida de Oliveira ${ }^{9}$
}

RESUMO: O artigo apresenta um relato do trabalho que vem sendo realizado no Centro de Educação Noturno da Bahia (CENEB) como parte do PIBID, dentro do subprojeto de Física, na linha de Educação de Jovens e Adultos (EJA), em uma turma do turno noturno, cujo perfil do alunado apresenta-se diferenciado daquele de ensino médio regular. Nesse sentido, optou-se por utilizar metodologias e estratégias de ensino, que levassem em consideração os conhecimentos cotidianos dos alunos numa aproximação com as ideias freireanas de educação. Para tanto, após o levantamento dos dados relativos aos aspectos econômicos e sociais da turma por meio de um questionário, foi aplicada uma sequência didática envolvendo os recursos das aulas expositivas tradicionais, com o uso slides e vídeos e atividades experimentais abordando os conteúdos de óptica, eletricidade e termodinâmica. Os resultados mostraram que as atividades realizadas atingiram os objetivos propostos, tornando o ensino de tópicos de Física dinâmico, divertido e atrativo. Vale ressaltar também que o PIBID tem exercido importante papel na formação dos licenciandos ao propiciar um contato mais breve dos mesmos com as redes de ensino, futuro local de trabalho desses profissionais.

Palavras-Chave: EJA; Ensino de Física; Experimentos; Didática.

\section{Introdução}

A Educação de Jovens e Adultos (EJA) é uma modalidade de ensino que visa atender àqueles que não tiveram oportunidade de estudar na idade própria, além de preparar o jovem e o adulto para o mercado de trabalho (ESCOLA, 2017). No entanto, a EJA não deve ser pensada como uma modalidade inferiorizada em comparação com o ensino regular, devendo ser elaboradas estratégias de ensino que superem a ideia de transferência de conhecimento.

Todos autores são vinculados à Universidade Estadual do Sudoeste da Bahia - UESB, curso de Física. Email para contato: jackcaribi@hotmail.com 
- Revista de Iniciação à Docência, v. 2, n. 1, 2017 Publicação: dezembro, 2017 - ISSN 2525-4332

Desde a década de 1970 que a EJA vem sendo discutida no país, porém pouco é falado sobre o Ensino de Física nessa modalidade de ensino. Dessa forma, estudos que versem sobre este tema são essenciais para que mais discussões sejam realizadas, não só no meio acadêmico como também em espaços escolares.

A educação de jovens e adultos (EJA) ainda é vista por alguns educadores como uma forma de alfabetizar quem não teve oportunidade de estudar na infância ou aqueles que, por algum motivo, tiveram que abandonar a escola regular. Os estudantes da EJA possuem um perfil heterogêneo do ponto de vista etário, mas homogêneo sobre a ótica da necessidade de trabalhar para o sustento familiar. Dessa forma, sendo uma modalidade de ensino diferente do ensino regular, demanda do educador uma postura pedagógica que leve em consideração esse perfil de alunos, bem como da utilização de estratégias de ensino, a exemplo de Sequências Didáticas (SD).

Para atender as demandas acerca da inserção de novos elementos relacionados ao mundo do trabalho, torna-se importante a utilização de estratégias de ensino que superem a ideia de transmissão do conhecimento, de modo que os alunos consigam entender e aplicar os conhecimentos em seu cotidiano, levando esse diferencial para o mundo do trabalho. No âmbito do Ensino de Física, tem sido unânime, entre os estudiosos do campo, o fato de que a utilização de atividades experimentais se constitui em importante estratégia de ensino.

Conforme afirma Silva (2007) aponta:

O objetivo do experimento é a derivação de inferências referentes a relações causais entre as características respostas relevantes e as características explanatórias que são definidas pelo problema e pela hipótese científica. Essas inferências são baseadas em uma amostra onde também estão presentes as características estranhas cujos efeitos sobre as características respostas ficam confundidos com efeitos das características explanatórias. Assim, essas inferências devem basear-se nos efeitos dessas duas origens e, particularmente, na relação entre esses efeitos (SILVA, 2007, p. 120)

Dessa forma, com a observação e participação dos alunos nos experimentos, é possível estabelecer uma relação dos conteúdos com o dia a dia, tornando assim mais eficaz a compreensão dos mesmos.

De um ponto de vista teórico, a concepção de educação que têm sustentado as intervenções na sala de aula e na realização das atividades tem sido baseada nos estudos de Paulo Freire, para quem

a questão da identidade cultural, de que fazem parte a dimensão individual e a de classe dos educandos, cujo respeito é absolutamente fundamental na prática educativa progressista, é problema que não pode ser desprezado (Freire, 2001, p. 42). 
- Revista de Iniciação à Docência, v. 2, n. 1, 2017 Publicação: dezembro, 2017 - ISSN 2525-4332

Nesse sentido, as estratégias metodológicas adotadas aproximam-se das orientações e diretrizes para a modalidade de ensino da EJA. A experiência de vida do alunado foi uma de nossas ferramentas em sala de aula, pois servia como alicerce para o entendimento das teorias, que por vezes são demasiadamente abstratas. Sempre que possível os conteúdos eram apresentados e discutidos com os alunos de uma forma que pudessem ser relacionados com as suas experiências diárias, visando aumentar o interesse pelo assunto abordado, bem como eliminar a impressão de que a física é uma disciplina de difícil de entendimento, contribuindo para minimizar a grande evasão escolar, tão presente nessa modalidade de ensino.

$O$ presente trabalho apresenta um relato das atividades que vêm desenvolvidas em uma turma da EJA, no Centro Noturno de Educação da Bahia (CENEB), em Vitória da Conquista, Bahia, no ano 2017, no âmbito do Programa Institucional de Bolsas de Iniciação à Docência (PIBID), no subprojeto de Física.

\section{Metodologia}

Inicialmente elaboramos um questionário composto de questões fechadas abordando as seguintes dimensões: identificação pessoal, situação social, econômica, cultural e escolarização. O objetivo foi identificar o perfil dos alunos. A turma era composta por 35 alunos matriculados, sendo que apenas 28 responderam o questionário, que foi aplicado em duas horas/aula.

As estratégias de ensino envolvendo a Sequência Didática (SD) foram compostas pelas aulas expositivas, a apresentação de slides, os experimentos de baixo custo e a projeção de vídeos sobre os temas eletricidade e óptica, cujo objetivo era melhorar o desempenho e a aprendizagem dos alunos. A Sequência Didática (SD) foi composta de 14 atividades, sendo seis delas para o estudo de energia elétrica tensão elétrica, corrente elétrica, potência elétrica; 4 atividades para o estudo de óptica, e 4 para o estudo da termodinâmica, sendo 2 aulas com experimentos de baixo custo, totalizando 12 encontros.

Ao final foi aplicado um questionário composto de perguntas sobre os conteúdos abordados, com o intuito de avaliar a aprendizagem dos estudantes participantes.

Para a análise e discussão dos resultados obtidos foram considerados os dados obtidos por meio dos questionários juntamente com a observação e o registro fotográfico de momentos das atividades realizadas. Outras fontes de informação foram constituídas por artigos científicos publicados em revistas, além de páginas virtuais de eventos e periódicos publicados na rede mundial de computadores. 
- Revista de Iniciação à Docência, v. 2, n. 1, 2017 Publicação: dezembro, 2017 - ISSN 2525-4332

\section{Resultados e Discussão}

\section{O perfil dos estudantes:}

Conhecer o perfil do alunado da EJA é entender que estes sujeitos têm necessidades educacionais próprias e específicas, desta forma, estabelecer inferências a respeito de uma diretriz para o ensino-aprendizagem da Física.

Nesta turma estavam matriculados 35 alunos, mas apenas 32 alunos frequentavam as aulas regularmente; 28 (80\%) responderam o questionário, sendo 16 do sexo feminino e 12 do masculino. Todos têm idade acima de 18 anos.

Verificamos que nessa turma os jovens e adultos exercem profissões/ocupações de baixa remuneração. Perguntamos sobre a cor ou raça/etnia segundo os critérios do IBGE, com a maioria dos alunos, ou seja, 16 pessoas responderam que são pardas, como mostra o gráfico abaixo:

Gráfico 1. Quantidade de alunos segundo os critérios do IBGE sobre cor/etnia.

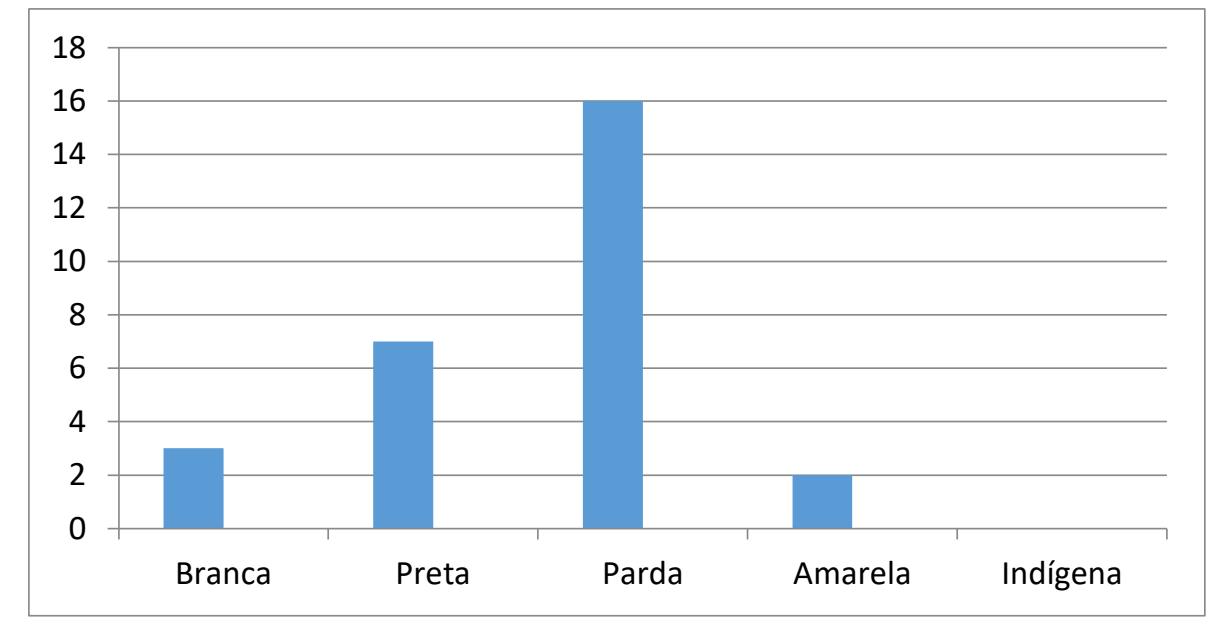

Fonte: Dados da Pesquisa.

Com relação à escolaridade dos pais, 32\% (9 pessoas) responderam que o pai estudou até o ensino fundamental I, enquanto que 9 pessoas (maioria) responderam que a mãe possui o ensino fundamental II. Verificamos também que 16 pessoas são beneficiárias de algum programa social do governo Federal, Estadual ou Municipal. Observamos, como mostra o gráfico abaixo, que eles gostam/tem costume de frequentar festivais em Vitoria da Conquista/BA. 
- Revista de Iniciação à Docência, v. 2, n. 1, 2017 Publicação: dezembro, 2017 - ISSN 2525-4332

Gráfico 2. Quantidade de alunos que frequentam atividades culturais em Vitória da Conquista/BA.

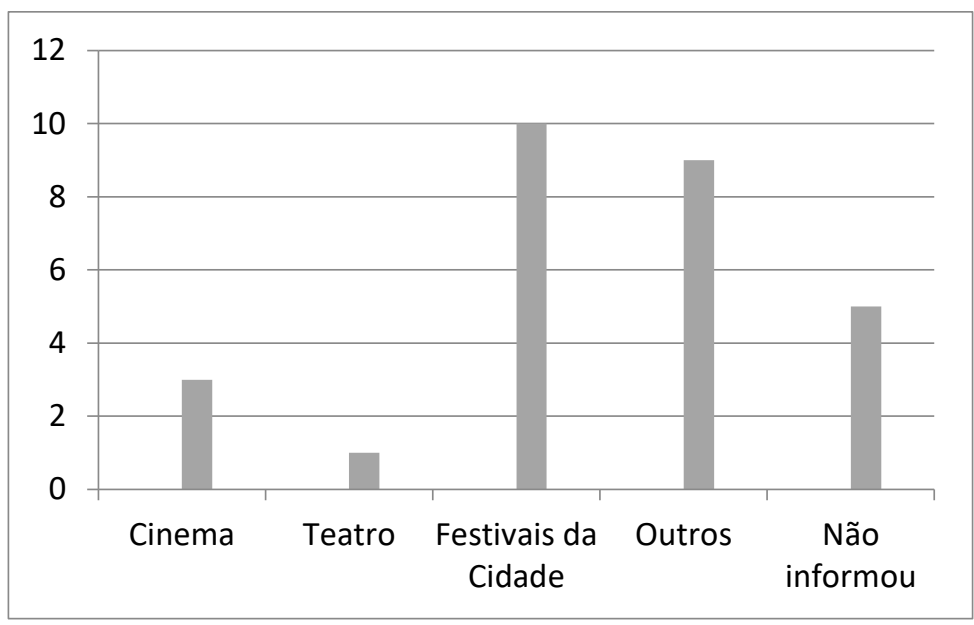

Fonte: Dados da Investigação.

Quanto às fontes de informações, a internet se constitui no principal meio de obtê-las, sendo que 21 pessoas mencionaram ter acesso via celular.

É interessante ressaltar que 21 alunos querem dar continuidade ao processo formal de estudos, pretendendo ingressar numa instituição de educação superior.

Gráfico 3. Quantidade de alunos que pretendem dar continuidade no processo formal de estudos.

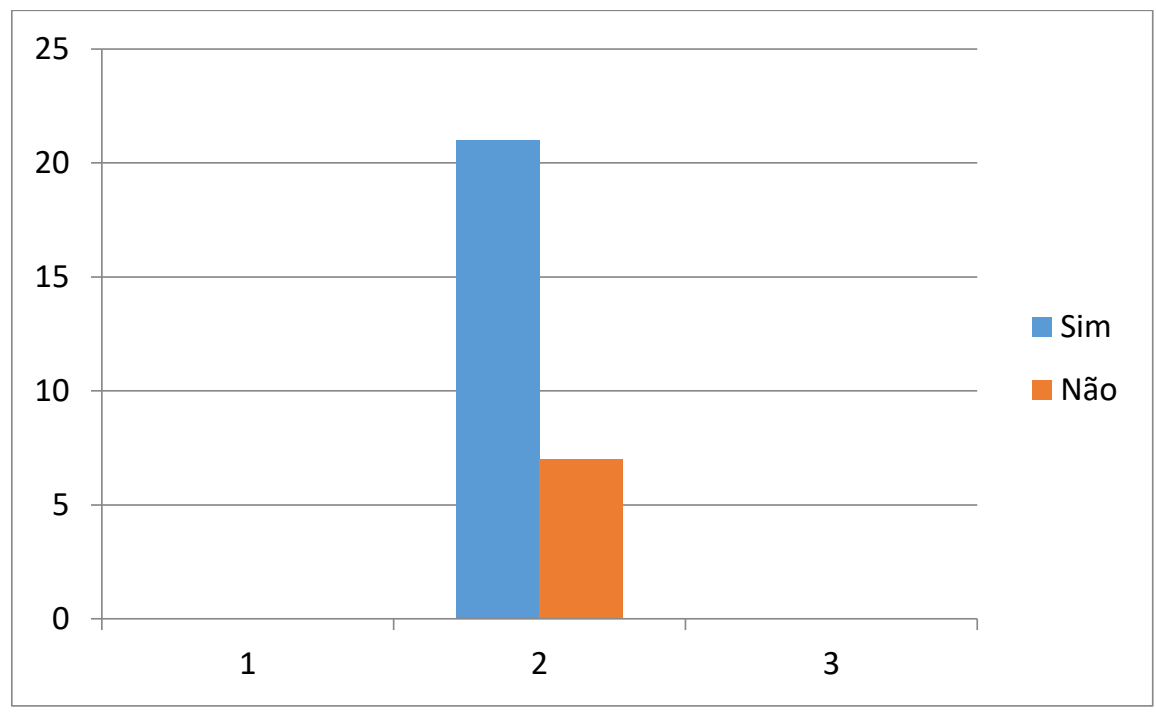

Fonte: Dados da Investigação.

Colocamos em evidência esses dados que mostram que os educandos não pensam apenas na conclusão do Ensino Médio, mas sim, buscam melhor qualidade de vida nos aspectos sociais e profissionais, contrastando com informações obtidas em um trabalho sobre a EJA, que realizamos em uma escola anterior a atual. 


\section{- Revista de Iniciação à Docência, v. 2, n. 1, 2017 - Publicação: dezembro, 2017 - ISSN 2525-4332}

\section{A Sequência Didática:}

Consoante com as nossas expectativas, observamos que as aulas com o uso de slides apresentaram uma grande dinamicidade, com um bom aproveitamento dos conteúdos ensinados, proporcionando uma otimização do tempo da aula, o qual era utilizado para discussões, solução de dúvidas e esclarecimentos junto aos alunos. Constatamos também que as aulas aplicadas com o uso dos vídeos apresentaram um rendimento semelhante às aulas com o recurso de slides, sendo que o som, as imagens, o "ver acontecer" estimulava os alunos a pensarem e a quererem participar da discussão do tema abordado.

Estas duas ferramentas se mostraram eficientes no ensino, pois possibilitaram o trabalho minucioso que em uma aula tradicional, muitas vezes, não é possível de ser realizado. Podemos citar como exemplos, a elaboração de uma ideia mais "refinada", o enunciado de uma lei, os comentários e a análise de um fenômeno físico, que por vezes são tarefas complexas, que envolvem processos de abstração dificultando o entendimento dos alunos e deixando-os intimidados com a teoria.

\section{As Atividades Experimentais:}

A experimentação foi a terceira ferramenta empregada no ensino da termodinâmica. As figuras 1 e 2 apresentam a realização de experimentos de baixo custo sobre conceitos de termodinâmica, enquanto que nas figuras 3 e 4, ilustram momentos de realização de experimentos que versavam sobre a condução de calor em diferentes materiais, nas quais percebemos uma maior interação dos alunos na realização das atividades. Notamos que, com as atividades experimentais, o envolvimento espontâneo dos alunos na aula foi bem maior, sendo perceptível também o interesse por parte da maioria, pois, os experimentos os envolvem, trazendo uma nova forma de aprendizado, no qual os alunos podem interagir com o assunto abordado na aula.

Figura 1: A bexiga que não estoura.

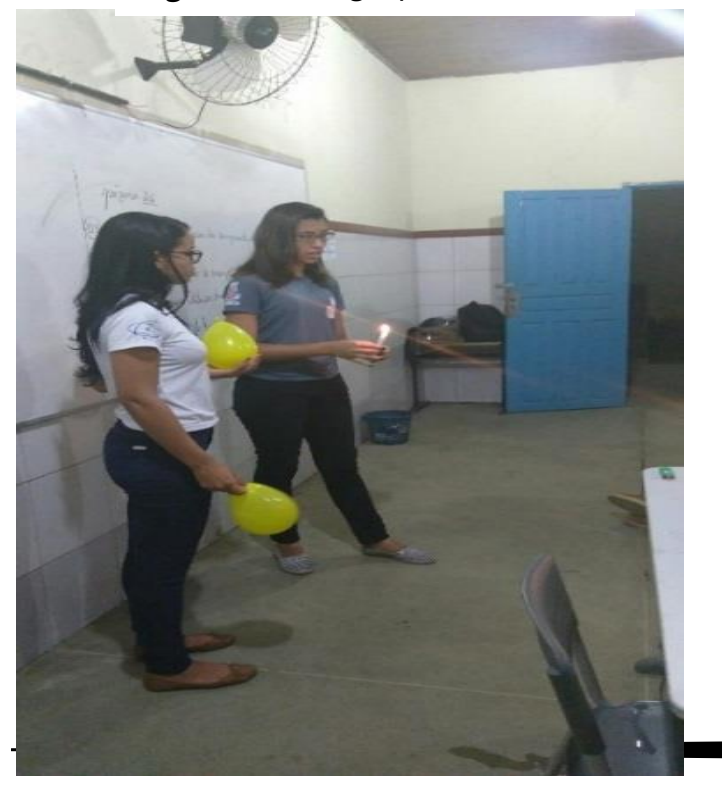

Figura 2: A gangorra de fogo.

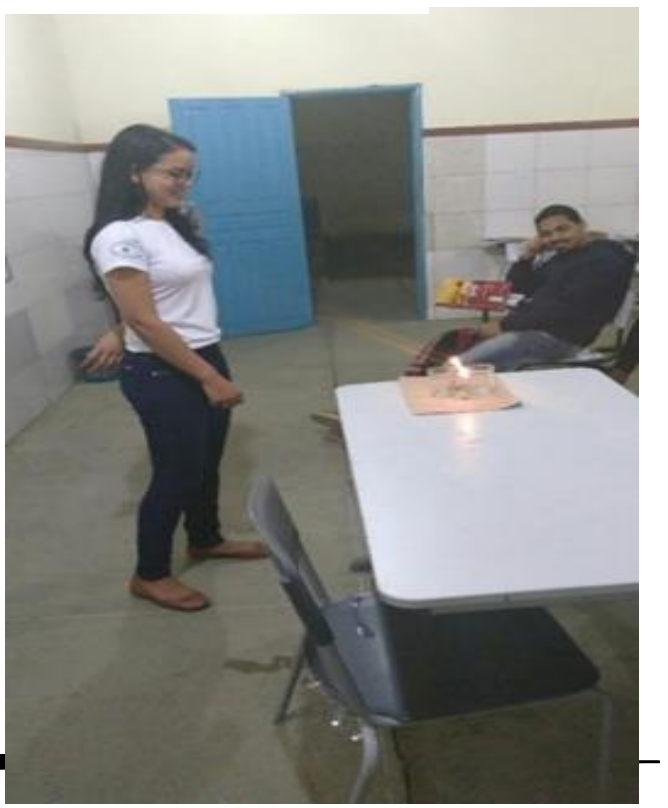


- Revista de Iniciação à Docência, v. 2, n. 1, 2017 Publicação: dezembro, 2017 - ISSN 2525-4332

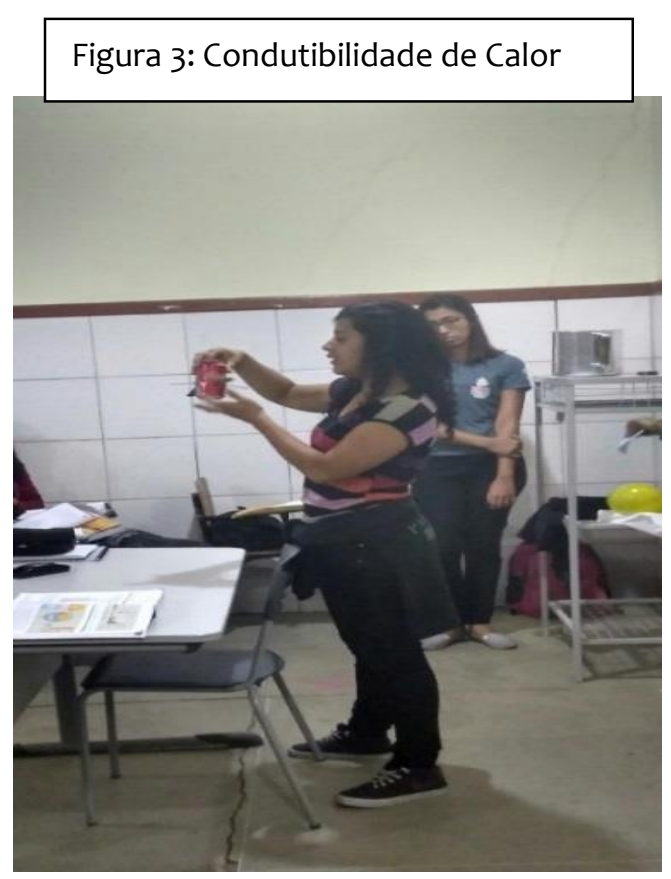

Figura 4: Alunos interagindo.

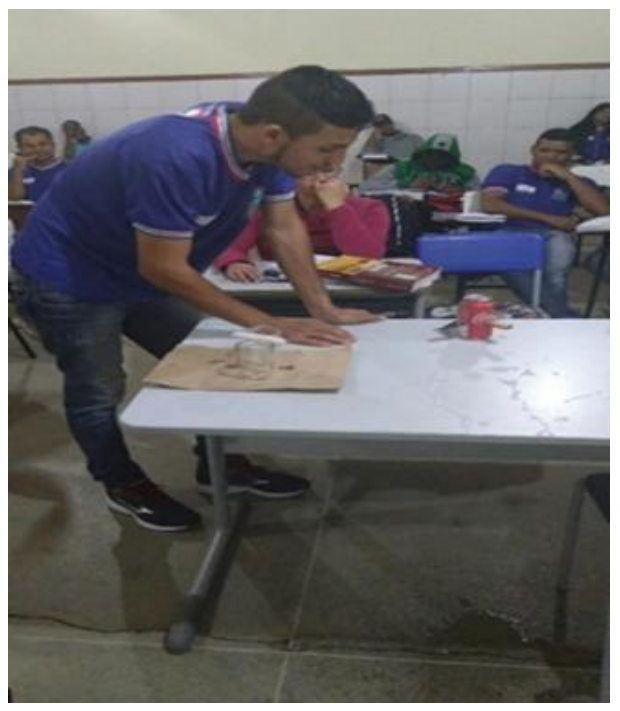

\section{Algumas respostas para o Questionário Final:}

Diante da pergunta: Sua compreensão sobre a física mudou após as aulas? Observamos que 17 alunos responderam que sim, enquanto 4 responderam que não e 7 não informaram, o que nos leva à conclusão de que as metodologias propostas nas atividades desenvolvidas contribuíram para uma mudança de concepção dos alunos sobre os conhecimentos físicos.

Gráfico 4. Respostas dos participantes à questão do questionário final.

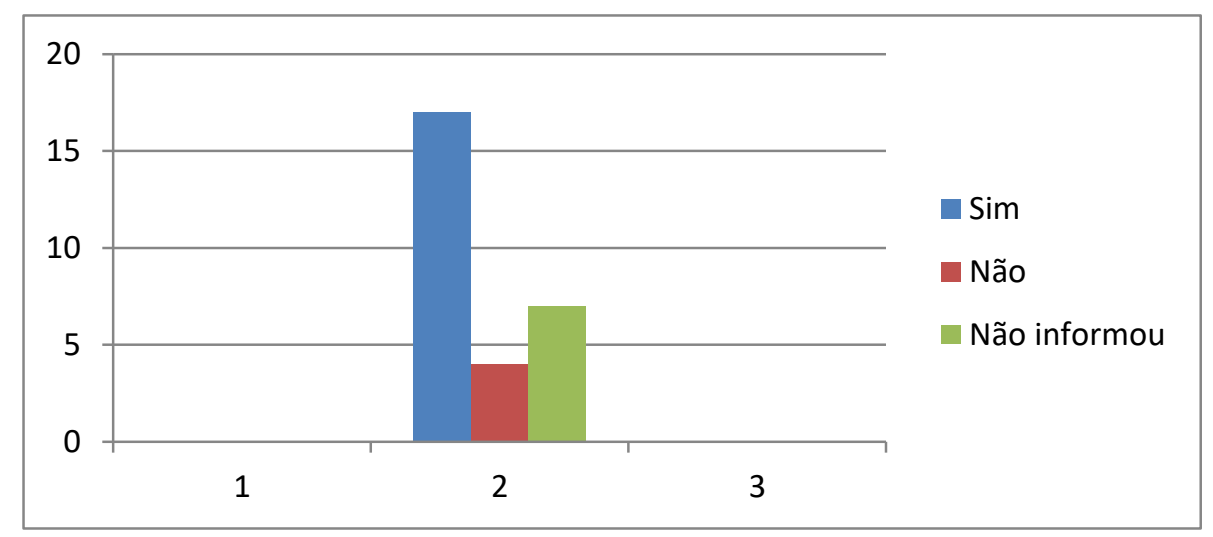

Fonte: Dados da Investigação.

Diante da pergunta: Se você fosse um professor que estratégias utilizaria para que seu aluno compreendesse a matéria? Nas respostas, obtivemos 23 afirmações diferentes, dentre elas destacamos algumas:

"Elaboraria experimentos" (Aluno A).

"Humor e muita atenção ao aluno" (Aluno B). 
- Revista de Iniciação à Docência, v. 2, n. 1, 2017 Publicação: dezembro, 2017 - ISSN 2525-4332

"Experimentos e vídeo aulas, assim como vocês (bolsistas) trabalham" (Aluno C)

"Explicar bem o conteúdo a ser passado" (Aluno D).

"Em forma de dinâmicas" (Aluno E).

"As mesmas que o professor usa" (Aluno F).

Percebemos através das falas dos alunos a importância de trabalhar com experimentos e vídeos na sala de aula, o que além de ser uma contribuição essencial para os educadores, constitui-se numa forma dos educandos visualizarem o que estudaram na teoria.

\section{Considerações Finais}

A física tem sido vista no âmbito da educação básica, como uma disciplina de difícil compreensão pelos estudantes e quando não é assimilada, tende a causar uma repulsa generalizada. Foi nesse cenário que começamos o nosso trabalho e com um pouco de esforço e paciência procuramos mostrar que a Física está presente no nosso dia a dia.

A turma é composta por estudantes das classes populares que têm uma longa jornada de trabalho durante o dia, normalmente exercendo profissões de baixa remuneração. Por outro lado, voltaram a estudar visando a conclusão do Ensino Médio, não somente buscando um futuro melhor no mercado de trabalho, mas também com o objetivo de ampliar essa possibilidade por meio do Ensino Superior. Trata-se também de um grupo que vive conectado ao mundo virtual obtendo informações do cotidiano por meio das redes sociais. Quanto aos aspectos socioculturais ficou evidenciado que são educandos que gostam e participam de atividades culturais oferecidas na cidade. Por fim, são novos sujeitos e novas histórias de vida que estão sendo construídas.

A deficiência aguda dos estudantes em Matemática foi um grande empecilho, mas com atitudes coerentes conseguimos familiarizá-los com a parte conceitual da Física. O trabalho experimental se mostrou favorável, tendo em vista o interesse dos alunos em participar e interagir nas aulas, o que favoreceu a aprendizagem dos conteúdos abordados, embora esse tipo de atividade seja pouco presenciado tanto na EJA como no ensino médio de Física.

Para os bolsistas, em processo de formação, juntamente com o professor supervisor fica a certeza que os professores devem estar sempre em busca de inovação, com o intuito de prender à atenção dos alunos, afim de diminuir o índice de rejeição à disciplina. 
- Revista de Iniciação à Docência, v. 2, n. 1, 2017 Publicação: dezembro, 2017 - ISSN 2525-4332

Nesse sentido, o Projeto Institucional de Bolsas de Iniciação à Docência PIBID tem sido de grande importância na formação acadêmica dos bolsistas, pois oferece a oportunidade deles trabalharem no futuro ambiente de trabalho. Particularmente quanto à linha de ação EJA, tem sido uma experiência relevante, por tratar-se de um público com características diferentes do normal, necessitando, portanto, de maior atenção por parte de todos os professores.

Por fim, ressaltamos que os dados obtidos se aproximam daqueles encontrados na literatura, o que nos permite vislumbrar a elaboração de estratégias de acordo com a análise do perfil destes educandos, com vistas a que tanto professor, bolsistas e alunos possam chegar ao final do ano letivo com resultados positivos e significativos.

\section{Referências}

ESCOLA, I. (25 de setembro de 2017). Infor Escola. Fonte: Infor Escola: navegando e aprendendo. Disponível em: < https://www.infoescola.com/>.

FREIRE, P. Pedagogia da Autonomia: saberes necessários à pratica educativa. São Paulo: Paz e Terra, 2001.

SILVA, J. G. Estatística Experimental: planejamento de experimentos. Pelotas/RS: UFPEL; Instituto de Física e Matemática, 2007. 